\title{
EVALUATION OF MR RELAXATION TIMES FOLLOWING TRASTUZUMAB TREATMENT OF BREAST CANCER CELLS IN A 3D BIOREACTOR
}

\author{
DOROTA BARTUSIK-AEBISHER ${ }^{1 *}$, DAVID AEBISHER ${ }^{1}$, ANNA CZMIL $^{2}$ \\ and DAMIAN MAZUR ${ }^{2}$
}

\author{
${ }^{1}$ Faculty of Medicine, University of Rzeszow, Poland
}

${ }^{2}$ Rzeszow Polytechnic, Rzeszow, Poland

\begin{abstract}
The three-dimensional tumor environment can be mimicked with the use of cells cultured within a hollow-fiber bioreactor (HFBR). In this work, magnetic resonance imaging (MRI) was used to monitor changes in relaxation time in breast cancer cells following treatment with Trastuzumab in an HFBR system. Breast cancer cells were inoculated into the HFBR system and cultured over a period of 4 weeks. Relaxation time maps were generated according to MRI techniques in three dimensional (3D) cultures of MCF7/Her2 breast cancer and MCF7/Neo4 control cells. MRI measurements showed a variation in values of spin-lattice $\left(\mathrm{T}_{1}\right)$ and spinspin $\left(T_{2}\right)$ relaxation times related to cell density. Differences in both values $\left(T_{1}\right.$ and $\left.T_{2}\right)$ were noted between untreated cells and cells treated with trastuzumab in the HFBR device. Additionally, ${ }^{1} \mathrm{H}$ MRI was able to provide information about drug penetration in breast cancer cell culture organized in 3D. In conclusion, MRI in vitro can provide direct, noninvasive visualization of cell density in 3D geometry and cell viability as a function of drug uptake. Both $\mathrm{T}_{1}$ and $\mathrm{T}_{2}$ values were higher for lower cell density and accordingly both values, $\mathrm{T}_{1}$ and $\mathrm{T}_{2}$, were lower for higher cell density.
\end{abstract}

Keywords: breast cancer cell cultures, hollow-fiber bioreactor (HFBR), relaxation time maps, magnetic resonance imaging (MRI)

Breast cancer is the most frequently occurring cancer in women worldwide with more than one million new cases diagnosed each year. The poor prognosis for many cases is due to the complexity of treatments with a lack of precise monitoring of drug action in vivo (1-6). Therefore, therapies are needed with improved methodologies to monitor cancer drug delivery and effectiveness (7-11). In this paper, we present a study of MRI measurements in breast cancer cell cultures grown in three dimensions (3D). Based on morphology, cell death can be characterized as apoptotic where the nucleus undergoes early degeneration, or necrotic when the cell membrane and organelles show early degeneration (12). In the present study, we investigated changes in relaxation time following treatment with trastuzumab in human breast cancer cells. We developed 3D cell cultures that differ in Her2 receptor expression and sensitivity to trastuzumab. Trastuzumab is a monoclonal antibody that targets the Her2 receptor and is used together with chemotherapy in the treatment of breast cancer in patients whose tumors overexpress the Her2 receptor. Although this therapy has extended disease-free survival in a significant number of patients, not all Her2 overexpressing tumors respond to this treatment, and some develop resistance after an initial response. The efficiency of this therapy is very low in a significant number of patients and this therapy is not curative in many cases. In this study, we sought to determine if spin relaxation times associated with trastuzumab uptake could be objectively quantified by MRI. In a previous study, we reported spin-spin $\left(\mathrm{T}_{2}\right)$ measurements in cells treated with trastuzumab, and these results allowed for visualization of cells non-invasively by MRI (13). Therefore, we would like to continue to use cellular MRI as a research tool in clinical settings and for monitoring cell-based regenerative therapies. We are interested in monitoring drug action and uptake in 3D cell culture by MRI. Cellular MRI in 3D culture is a tool uniquely suited to this task, given its ability to deeply image 3D cell cultures with high temporal resolution and sensitivity. The spin-spin relaxation time of water is known to be related to water content and

* Corresponding author: e-mail: dbartusik-aebisher@ur.edu.pl 
membrane permeability (13). Thus, for constant membrane permeability, a decrease in the water content should induce a decrease in $\mathrm{T}_{2}$. Moreover, the $\mathrm{T}_{2}$ of water is sensitive to the structure and the mobility of the surrounding molecules through chemical exchange and dipole-dipole interactions. Therefore, a change in non-aqueous molecular mobility should induce a change in the $T_{2}$ of water.

\section{EXPERIMENTAL}

\section{Three dimensional tumor model in vitro}

Human MCF7 cell line was obtained from American Type Culture Collection (ATCC, Rockville, MD). All cell culture procedures were conducted in a sterile class II biological safety cabinet (Bio Hood 2, MICROZONE). In the case of tumor and normal breast cells, in vitro conditions were applied.

\section{MCF7/Her2 and MCF7/Neo4}

The MCF7/Her2 cell line was cultured in RPMI media (Biofluids) and containing 5\% fetal calf serum (Biofluids), $2 \mathrm{mM}$ glutamine, 50 units $/ \mathrm{mL}$ penicillin and $50 \mu \mathrm{g} / \mathrm{mL}$ streptomycin. MCF7/Her2 is obtained from MCF-7 cells that are transfected with Her2-cDNA. MCF7/Her2 are stable transfected cells that overexpress Her2. Her2 overexpression of these cell lines was confirmed with cytometric analysis (14). The MCF7/Neo4 cell line was cultured in DMEM media at the ratio $1: 1$ with $2 \mathrm{mM}$ L-glutamine, $50 \mu \mathrm{g} / \mathrm{mL}$ streptomycin sulfate and $10 \mu \mathrm{g} / \mathrm{mL}$ gentamicin sulfate supplemented with 1.5 IU/mL IL-2 containing 4-fold concentrations of amino acids and vitamins and $4500 \mathrm{mg} / \mathrm{L}$ of glucose. MCF7/Neo4 are cells that are resistant to the antibiotic neomycin and were used as control.

\section{Three dimensional (3D) cultures}

Cells $\left(10^{5}\right.$ cells $/ \mathrm{mL}$ of MCF-7/Her2 or MCF7/Neo4) were seeded in the HFBR device (FiberCell Systems Inc., Frederick, MD). The HFBR is a closed-loop system that consists of porous hydrophilic hollow fibers with $0.1 \mu \mathrm{m}$ size pores in polysulfone tubing. For this study, we used one fiber in each HFBR cartridge. All but one fiber was removed from the cartridge prior to inoculation. In our experiments, the use of one fiber enables selection of a region of cells in which $T_{1}$ and $T_{2}$ are measured without interference. After inoculation, the bioreactors were perfused and maintained in an atmosphere of $5 \% \mathrm{CO}_{2}, 95 \%$ air at $37^{\circ} \mathrm{C}$. The flow of medium was initially $\sim 5 \mathrm{~mL} /$ minute and gradually increased over the next 10 days to a rate of $14 \mathrm{~mL} /$ minute. The perfusion medium was changed twice weekly. Control bioreactors received fresh medium throughout the 4-week culture period. For our study, cell cultures grown on one fiber yielded a sufficient number and density of cells. The fiber in the bioreactor was pre-cultured with $250 \mathrm{~mL}$ of phosphatebuffered saline (PBS), followed by two changes of cell culture medium (first with medium without serum and finally with the complete medium). The purpose of the pre-culture was to remove the wetting agent from the fibers, equilibrate the system with growth medium and serum proteins, and verify that the system is leak-free and sterile. In the humidified incubator, equilibration of the HFBR system was achieved by overnight recirculation of $100 \mathrm{~mL}$ of medium. Cells were inoculated by syringe in a total volume of $11 \mathrm{~mL}$ of media into the extra capillary space of an HFBR cartridge. The medium flow rate was $14 \mathrm{~mL} / \mathrm{h}$ through the HFBR and this value was determined in a previous study of the influence of different flow rates $(7,14$, and $50 \mathrm{~mL} / \mathrm{h})$ on cell growth and viability in the $\operatorname{HFBR}(15,16)$. An HFBR system with no medium flow $(0 \mathrm{~mL} / \mathrm{h})$ served as control. Throughout the experiments, the reservoir (which was initially $100 \mathrm{~mL}$ and later increased to $150 \mathrm{~mL}$ ) was completely refilled with fresh media every $72 \mathrm{~h}$. At the same time, when the media reservoirs were being refilled, an aliquot was taken from the media and fresh media were placed into each system. These aliquots were utilized to determine glucose consumption and lactate production. The glucose consumed was determined by analyzing the glucose concentration within an aliquot prior to the reservoir being placed into the HFBR and within an aliquot taken from the same reservoir after it was removed from the HFBR. Lactate levels were measured using a commercial enzyme-linked immunosorbent assay kit (Sigma, Saint Louis, MO) according to manufacturer's recommendations. Similar to the glucose assay, aliquots from the reservoir were assayed prior to and following circulation in the system for lactate concentration.

\section{Trastuzumab treatment}

In our experience, MCF7/Her2 treatment with trastuzumab, as low as $0.010 \mu \mathrm{g} / \mathrm{mL}$, has a cytotoxic effect (12). Previously, we reported that trastuzumab concentrations of $0.05,0.5,50,100$ 200 , and $1000 \mu \mathrm{g} / \mathrm{mL}$ yields MCF7/Her2 cell viability of $80 \pm 1 \%, 77 \pm 4 \%, 74 \pm 2 \%, 70 \pm 3 \%, 66 \pm$ $4 \%, 63 \pm 3 \%$ and $61 \pm 1 \%$, respectively (16). In order to detect changes in $\mathrm{T}_{1}$ and $\mathrm{T}_{2}$ following treatment, cells in HFBR were treated with a 1000 $\mu \mathrm{g} / \mathrm{mL}$ concentration of trastuzumab (16). 


\section{$T_{1}$ measurement}

All MRI experiments were performed using a 9.4 Tesla (T) magnet with a bore diameter of $21 \mathrm{~cm}$. Water proton longitudinal $\left(\mathrm{T}_{1}\right)$ relaxation times of both cell lines were measured using an inversion recovery (IR) pulse sequence with an echo time (TE) of $16.5 \mathrm{~ms}$, a repetition time (TR) of $8000 \mathrm{~ms}$, and eight inversion times (TIs) - 10, 100, 200, 400, $800,1000,2000$, and $4000 \mathrm{~ms} . \mathrm{T}_{2}$ relaxation times were measured using a multi-echo spin-echo (SE) pulse sequence with a TR of $8000 \mathrm{~ms}$ and 11 echoes $10 \mathrm{~ms}$ apart, with the first TE $16.5 \mathrm{~ms}$. The imaging plane was perpendicular to the long axis of the bioreactor. The field of view was $3 \times 3 \mathrm{~cm}$, the slice thickness of $2 \mathrm{~mm}$, and the matrix size $256 \times 256$.

\section{$\mathrm{T}_{2}$ measurement}

$\mathrm{T}_{2}$ relaxation times were measured using a multiecho spin-echo (SE) pulse sequence with a repetition time (TR) of $8000 \mathrm{~ms}$ and 11 echoes $10 \mathrm{~ms}$ apart with the first echo time (TE) $16.5 \mathrm{~ms}$. Field of View (FOV) was $1 \times 1 \mathrm{~cm}^{2}$ and matrix size was $256 \times 256$ and four averages. The imaging plane was perpendicular to the long axis of the capillary. The radiofrequency (rf) coil was made of $2 \mathrm{~mm}$ copper wire, six turns and the inner diameter was $3 \mathrm{~mm}$ and tuned to $400 \mathrm{MHz}$ which corresponds to the proton Larmour frequency at $9.4 \mathrm{~T}$. The image resolution was $39 \mu \mathrm{m}$.

\section{RESULTS}

Table 1 presents $T_{1}$ and $T_{2}$ measurements of $3 \mathrm{D}$ MCF7/Her2 cell cultures $(\mathrm{N}=12)$ before and after treatment with trastuzumab. The images displayed spatial maps of shallow, middle and deep levels of cell distribution that correspond to various signal intensity. Shallow, middle and deep represent different cell densities along the axial slice. The relaxation time profiles for shallow, middle and deep are generated based on variable cell density as indicated by decreasing $T_{1}$ and $T_{2}$ values (the greater the cell density, the lower the $T_{1}$ and $T_{2}$ ). The cells grow on the fiber in a homogeneous cylindrical shape along the fiber's length. As mentioned previously, in a particular axial slice perpendicular to the fiber length, cell density was greater in the deep layers closest to the fiber than cells on the periphery.

We quantified the response to treatment by MRI by determination of $T_{1}$ and $T_{2}$ after $72 \mathrm{~h}$. MCF7/Her2 cells exposed to treatments with
A

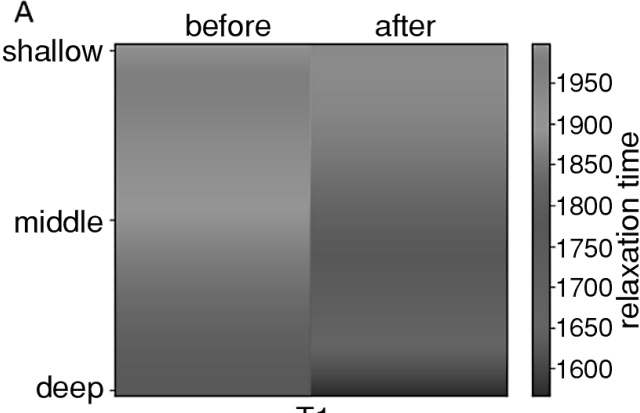

$\mathrm{T} 1$

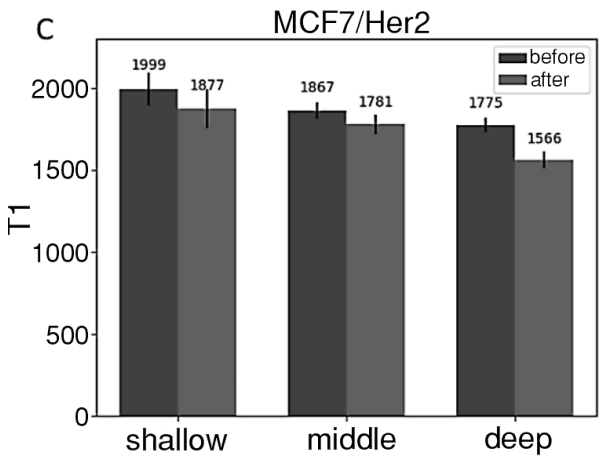

B
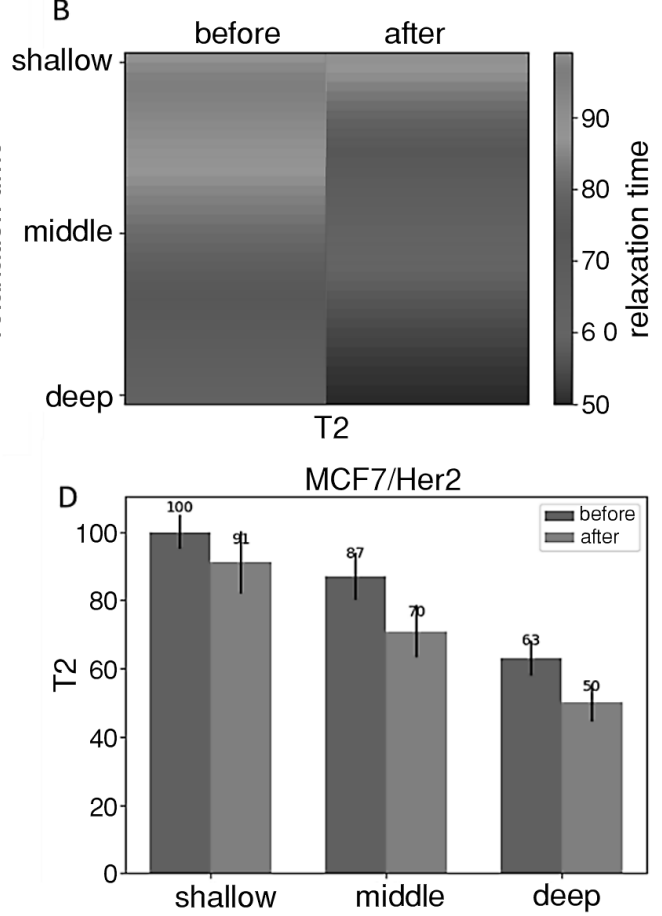

Figure 1. A) and C) $\mathrm{T}_{1}$ of 3D MCF7/Her2 cells cultures pre- and post-trastuzumab treatment; B) and D) $\mathrm{T}_{2}$ of 3D MCF7/Her2 cells cultures pre- and post-trastuzumab treatment. The presented data are mean values \pm standard deviation of twelve independent experiments. 
trastuzumab showed lower values of $T_{1}$ and $T_{2}$ as compared to cells before treatment. Both changes in $\mathrm{T}_{1}$ and $\mathrm{T}_{2}$ depended on cell viability. The viability of MCF7/Her2 cells measured with Trypan blue decreased substantially following $72 \mathrm{~h}$ of 1000 $\mu \mathrm{g} / \mathrm{mL}$ trastuzumab treatment. The treatment time of $72 \mathrm{~h}$ was chosen based on results from a previous study that showed that longer treatment times do not decrease MCF7/Her2 viability (16). Moreover, by using large concentrations of Trastuzumab, early responses and cellular changes were detected. MRI results are the effects caused by the loss of cellular water and cell membrane integrity that allows for the exchange of macromolecules and decreases in water, which distinguishes viable from non-viable cells.

Table 2 presents $\mathrm{T}_{1}$ and $\mathrm{T}_{2}$ measurements of $3 \mathrm{D}$ $\mathrm{MCF} 7 / \mathrm{Neo} 4$ cell cultures $(\mathrm{N}=12)$ pre- and posttreatment with trastuzumab.

Table 1. MRI characteristic of 3D MCF7/Her2 cell cultures.

\begin{tabular}{|c|c|c|c|c|c|c|}
\hline Level & $\begin{array}{c}\mathrm{T}_{1} \text { before } \\
(\mathrm{ms})\end{array}$ & $\begin{array}{c}\mathrm{T}_{2} \text { before } \\
(\mathrm{ms})\end{array}$ & $\begin{array}{c}\text { Viability } \\
\text { before }\end{array}$ & $\begin{array}{c}\mathrm{T}_{2} \text { after } \\
(\mathrm{ms})\end{array}$ & $\begin{array}{c}\mathrm{T}_{1} \text { after } \\
(\mathrm{ms})\end{array}$ & $\begin{array}{c}\text { Viability } \\
\text { after }\end{array}$ \\
\hline Shallow & $1999 \pm 100$ & $100 \pm 5$ & $100 \pm 2$ & $91.1 \pm 9.1$ & $1877 \pm 120$ & $25 \pm 4$ \\
\hline Middle & $1867 \pm 50$ & $87 \pm 7$ & $100 \pm 3$ & $70.9 \pm 7.6$ & $1781 \pm 58$ & $33 \pm 2$ \\
\hline Deep & $1775 \pm 43$ & $63 \pm 5$ & $100 \pm 2$ & $50.0 \pm 5.6$ & $1566 \pm 50$ & $24 \pm 4$ \\
\hline
\end{tabular}

Table 2. MRI characteristic of 3D MCF7/Neo4 cell cultures.

\begin{tabular}{|c|c|c|c|c|c|c|}
\hline Level & $\begin{array}{c}\mathrm{T}_{1} \text { before } \\
(\mathrm{ms})\end{array}$ & $\begin{array}{c}\mathrm{T}_{2} \text { before } \\
(\mathrm{ms})\end{array}$ & $\begin{array}{c}\text { Viability } \\
\text { before }\end{array}$ & $\begin{array}{c}\mathrm{T}_{2} \text { after } \\
(\mathrm{ms})\end{array}$ & $\begin{array}{c}\mathrm{T}_{1} \text { after } \\
(\mathrm{ms})\end{array}$ & $\begin{array}{c}\text { Viability } \\
\text { after }\end{array}$ \\
\hline Shallow & $1844 \pm 120$ & $82 \pm 4.1$ & $100 \pm 6$ & $1878 \pm 20$ & $71.1 \pm 41$ & $100 \pm 3$ \\
\hline Middle & $1281 \pm 68$ & $70 \pm 1.6$ & $97 \pm 4$ & $1581 \pm 68$ & $60.9 \pm 2$ & $97 \pm 10$ \\
\hline Deep & $1466 \pm 90$ & $56 \pm 1.6$ & $100 \pm 2$ & $1666 \pm 73$ & $40.0 \pm 3$ & $99 \pm 4$ \\
\hline
\end{tabular}

Table 3. Characterization of 3D MCF7/Her2 cell culture. The differences in \% between shallow, middle and deep tissue level.

\begin{tabular}{|c|c|c|c|}
\hline Level & Shallow & Middle & Deep \\
\hline Shallow & $0^{\mathrm{a}}, 0^{\mathrm{b}}, 0^{\mathrm{c}}, 0^{\mathrm{d}}, 0^{\mathrm{e}}, 0^{\mathrm{f}}$ & $\begin{array}{c}6.61^{\mathrm{a}}, 13^{\mathrm{b}}, 0^{\mathrm{c}}, 22.18^{\mathrm{d}}, \\
5.12^{\mathrm{e}}, 24.25^{\mathrm{f}}\end{array}$ & $\begin{array}{c}11.21^{\mathrm{a}}, 37^{\mathrm{b}}, 0^{\mathrm{c}}, 45.12,0^{\mathrm{d}}, \\
16.57^{\mathrm{e}}, 26.07^{\mathrm{f}}\end{array}$ \\
\hline \multirow{2}{*}{ Middle } & $\begin{array}{c}6.61^{\mathrm{a}}, 13^{\mathrm{b}}, 0^{\mathrm{c}}, 22.18^{\mathrm{d}}, \\
5.12^{\mathrm{e}}, 24.25^{\mathrm{f}}\end{array}$ & $0^{\mathrm{a}}, 0^{\mathrm{b}}, 0^{\mathrm{c}}, 0^{\mathrm{d}}, 0^{\mathrm{e}}, 0^{\mathrm{f}}$ & $\begin{array}{c}4.93^{\mathrm{a}}, 27.59^{\mathrm{b}}, 0^{\mathrm{c}}, 28.58^{\mathrm{d}}, \\
12.03^{\mathrm{e}}, 4^{\mathrm{f}}\end{array}$ \\
\hline Deep & $\begin{array}{c}11.21^{\mathrm{a}}, 37^{\mathrm{b}}, 0^{\mathrm{c}}, 45.12,0^{\mathrm{d}}, \\
16.57^{\mathrm{e}}, 26.07^{\mathrm{f}}\end{array}$ & $\begin{array}{c}4.93^{\mathrm{a}}, 27.59^{\mathrm{b}}, 0^{\mathrm{c}}, 28.58^{\mathrm{d}}, \\
12.03^{\mathrm{e}}, 4^{\mathrm{f}}\end{array}$ & $0^{\mathrm{a}}, 0^{\mathrm{b}}, 0^{\mathrm{c}}, 0^{\mathrm{d}}, 0^{\mathrm{e}}, 0^{\mathrm{f}}$ \\
\hline
\end{tabular}

${ }^{\mathrm{a}}$ is $\mathrm{T}_{1}$ before treatment $(\mathrm{ms}),{ }^{b}$ is $\mathrm{T}_{2}$ before treatment $(\mathrm{ms})$, cis viability before treatment, ${ }^{\mathrm{d}}$ is $\mathrm{T}_{1}$ after treatment $(\mathrm{ms}),{ }^{\mathrm{e}}$ is $\mathrm{T}_{2}$ after treatment (ms) and is viability after treatment.

Table 4. Characterization of 3D MCF7/Neo4 cell culture. The differences in \% between shallow, middle and deep tissue level.

\begin{tabular}{|c|c|c|c|}
\hline Level & Shallow & Middle & Deep \\
\hline \multirow{2}{*}{ Shallow } & $0^{\mathrm{a}}, 0^{\mathrm{b}}, 0^{\mathrm{c}}, 0^{\mathrm{d}}, 0^{\mathrm{e}}, 0^{\mathrm{f}}$ & $\begin{array}{c}30.6^{\mathrm{a}}, 14.64^{\mathrm{b}}, 3^{\mathrm{c}}, \\
15.82^{\mathrm{d}}, 14.35^{\mathrm{e}}, 3^{\mathrm{f}}\end{array}$ & $\begin{array}{c}20.5^{\mathrm{a}}, 31.71^{\mathrm{b}}, 0^{\mathrm{c}}, \\
11.29^{\mathrm{d}}, 34.32^{\mathrm{e}}, 1^{\mathrm{f}}\end{array}$ \\
\hline \multirow{2}{*}{ Middle } & $\begin{array}{c}6.61^{\mathrm{a}}, 13^{\mathrm{b}}, 0^{\mathrm{c}}, 22.18^{\mathrm{d}}, \\
15.82^{\mathrm{d}}, 14.35^{\mathrm{e}}, 3^{\mathrm{f}}\end{array}$ & $0^{\mathrm{a}}, 0^{\mathrm{b}}, 0^{\mathrm{c}}, 0^{\mathrm{d}}, 0^{\mathrm{e}}, 0^{\mathrm{f}}$ & $\begin{array}{c}12.62^{\mathrm{a}}, 20^{\mathrm{b}}, 0^{\mathrm{c}}, 5.11^{\mathrm{d}}, \\
33.34^{\mathrm{e}}, 2.7^{\mathrm{f}}\end{array}$ \\
\hline \multirow{2}{*}{ Deep } & $20.5^{\mathrm{a}}, 31.71^{\mathrm{b}}, 0^{\mathrm{c}}$, & $12.62^{\mathrm{a}}, 20^{\mathrm{b}}, 0^{\mathrm{c}}, 5.11^{\mathrm{d}}$, & $0^{\mathrm{a}}, 0^{\mathrm{b}}, 0^{\mathrm{c}}, 0^{\mathrm{d}}, 0^{\mathrm{e}}, 0^{\mathrm{f}}$ \\
\hline
\end{tabular}

${ }^{\mathrm{a}}$ is $\mathrm{T}_{1}$ before treatment $(\mathrm{ms})$, ${ }^{\mathrm{b}}$ is $\mathrm{T}_{2}$ before treatment $(\mathrm{ms})$, cis viability before treatment, ${ }^{\mathrm{d}}$ is $\mathrm{T}_{1}$ after treatment (ms), ${ }^{\text {e }}$ is $\mathrm{T}_{2}$ after treatment (ms) and is viability after treatment. 

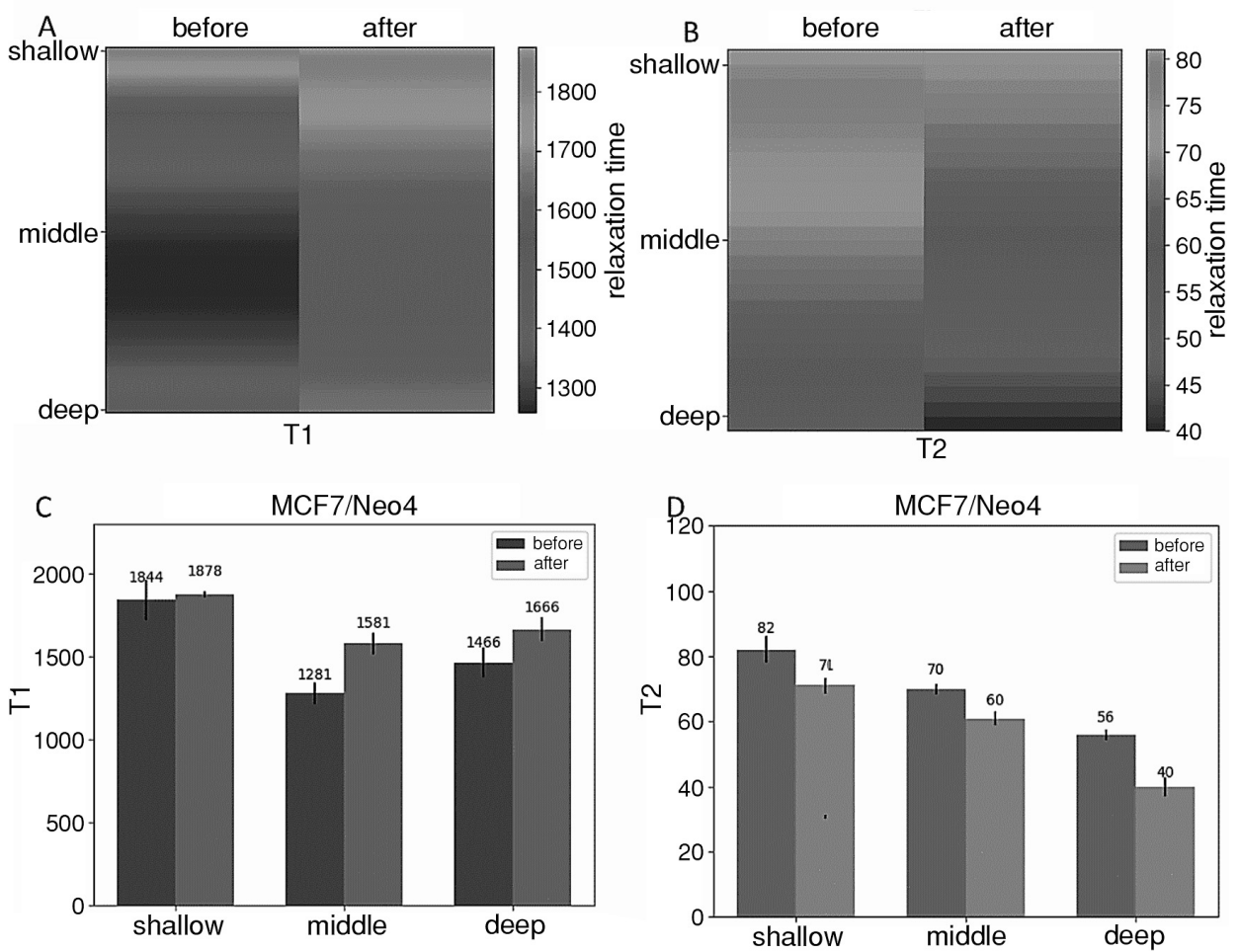

Figure 2. A) and C) $\mathrm{T}_{1}$ of 3D MCF7/Neo4 cell cultures pre- and post-treatment; B) and D) $\mathrm{T}_{2}$ of 3D MCF7/Neo4 cell cultures pre- and post-treatment. The presented data are mean values \pm standard deviation of twelve independent experiments.

The present data (Table 3 and Table 4) provides characterization by MRI of breast cancer cells in an in vitro system. Between shallow and middle, the $T_{1}$ and $T_{2}$ of breast cancer cells decrease before and after treatment.

The viability of MCF7/Neo4 cells measured with Trypan blue decreased. We quantified response to treatment. The values of $\mathrm{T}_{1}$ for $3 \mathrm{D}$ MCF7/Neo4 as compared to pre-treated cells did not decrease. The $\mathrm{T}_{2}$ decrease for 3D MCF7/Neo4 is observed in the range of $10 \mathrm{~ms}$ when compared to pre-treated cells. We observed that MRI shows differences in morphology of the cell line (Table 3 and Table 4). The treatment with trastuzumab was efficient only for cells where the Her-2 receptor was present.

\section{DISCUSSION}

In the present study, we investigated the association between cell density and relaxation time following by treatment by trastuzumab in a $3 \mathrm{D}$ model of breast cancer. We found that changes in cellular density associated with dead cells following trastuzumab uptake can be quantified by MRI. We found that both $\mathrm{T}_{1}$ and $\mathrm{T}_{2}$ relaxation time decreased with increasing cell density in the HFBR. This work is an extension of our work using MRI as a diagnostic imaging tool (13). Our data confirm that MRI can investigate fundamental properties of cells such as changes in cell density before and after treatment in a 3D cell culture that mimics a tumor. The development of cellular MRI acquisition and post-processing techniques for correlation properties in tissues with measurements such as $T_{1}$ and $T_{2}$ serve as preliminary studies for potential clinical application. There is a need for developing quantitative methods for mapping cell density within tissue (15) and our approach was to use MRI of 3D cell cultures. MRI in vitro measures parameters such as $\mathrm{T}_{1}$ and $\mathrm{T}_{2}$ which reflect changes in tissue composition and water content during drug treatment. This is accompanied by changes in magnetic resonance properties consistent with increased macromolecular content. Relaxation times are sensitive water content changes in tissue. Quantitative MRI measurements have been used in several studies to investigate plant tissues (17). The transverse relaxation time, $T_{2}$, is known to be affected by compartments which encompass water, and interactions between water and macromolecules (18). In general, the lower the 
mobility of water, the shorter the $\mathrm{T}_{2}$ relaxation time, so that the signal from water-bound within a polymer matrix decays away faster (1-100 ms) than that from free water. In solids, the signal decays away in less than $100 \mu$ s and this is usually not sufficient for spatial encoding to be applied (18). Clinical examples of $T_{1}$ relaxation time measurements include mean tissue water (19) and water in soleus muscle (20). Trastuzumab treatment rapidly decreased $\mathrm{T}_{1}$ and $\mathrm{T}_{2}$, for all cells with Her-2 expression. The first objective of this paper was to image cell density in 3D structure of cell cultures. The second objective of this paper was to measure $T_{1}$ and $T_{2}$ parameters in increasingly deeper layers of the $3 \mathrm{D}$ structure of the cell culture. In this work, we used quantitative MRI and hypothesized that $\mathrm{T}_{1}$ and $\mathrm{T}_{2}$ signal variation maps might predict the efficacy of cellular treatment. In our work published in 2013 (16), we demonstrated that $T_{2}$ maps of signal variation can predict the viability of cells. The first use of an HFBR in an NMR system was in 1990 (21) and HFBR was applied to MRI measurements of cell culture in 1997 (22). More recently, a bioreactor for measuring cellular metabolism by both fluorescence lifetime imaging microscopy and ${ }^{13} \mathrm{C}$ pyruvate MRI was reported (23) as well as an NMR tube bioreactor for ${ }^{31} \mathrm{P}$ cell viability measurements (24). Review articles on the use of bioreactors in NMR and MRI have been published recently $(25,26)$. In this paper, we have shown that in vitro MRI of MCF-7/Her2 and MCF7/Neo4 cells at $9.4 \mathrm{~T}$ allows monitoring of the cellular response to treatment with Trastuzumab. In vitro quantitative MRI studies of cell culture treatment may be applicable to clinical pathology.

\section{CONCLUSION}

MRI-based classification of cell density in 3D cell culture before and after treatment was performed using quantitative MRI parameters of $T_{1}$ and $T_{2}$ measurements. These findings suggest the benefit of incorporating quantitative MRI acquisitions in experimental evaluation of 3D cell cultures. MRI is a promising tool for the assessment of cancer cell density and viability properties after treatment with an anticancer drug. 3D cancer cells bioreactor techniques can be used to test the efficiency of treatment in many therapies. Additionally, the measurements of relaxation time are very promising in translation of our studies to in vivo therapies with trastuzumab.

\section{Acknowledgments}

Dorota Bartusik-Aebisher acknowledges support from the National Center of Science NCN (New drug delivery systems-MRI study, Grant OPUS-13 number 2017/25/B/ST4/02481).

\section{Conflict of interests}

The authors declare no conflict of interest.

\section{REFERENCES}

1. Cobleigh M.A., Vogel C.L., Tripathy D., Robert N.J., Scholl S., et al.: J. Clin. Oncol. 17, 2639 (1999).

2. Slamon D.J., Clark G.M., Wong S.G., Levin W.J., Ullrich A., McGuire W.L.: Science 235, 177 (1987).

3. Slamon D.J., Leyland-Jones B., Shak S., Fuchs H., Paton V., et al.: New. Eng. J. Med. 344, 783 (2001).

4. Burstein H.J., Kuter I., Campos S.M., Gelman R.S., Tribou L., et al.: J. Clin. Oncol. 19, 2722 (2001).

5. Esteva F.J., Valero V., Booser D., Guerra L.T., Murray J.L., et al.: J. Clin. Oncol. 20, 180008 (2002).

6. Piccart-Gebhart M.J., Procter M., LeylandJones B., Goldhirsch A., Untch M., et al.: N. Eng. J. Med. 353,1659 (2005).

7. Bartusik D., Tomanek B., Fallone G.: Med. Chem. Res. 19,1153 (2010).

8. Bartusik D., Tomanek B., Lattová E., Perreault H., Fallone G.: Biomed. Pharmacother. 64, 390 (2010).

9. Bartusik D., Tomanek B., Lattová E., Perreault H., Fallone G.: J. Pharm. Biomed. Anal. 51, 192 (2010).

10. Bartusik D., Aebisher D., Tomanek B.: J. Mol. Imag. Dynamics 2, 3 (2013).

11. O’Shaughnessy J.A., Vukelja S., Marsland T., Kimmel G., Ratnam S., Pippen J.E.: Clin. Breast Cancer 5, 142 (2004).

12. Vitale M., Zamai L., Mazzotti G., Cataldi A., Falcieri E.: Histochemistry 100, 223 (1993).

13. Bartusik D., Tomanek B.: Med. Chem. Res. 21, 2316 (2012).

14. Doeppler E.T.H., Yan I.K., Goodison S., Storz P.: Breast Cancer Res. 11, R13 (2009).

15. Archer B., Ueberrueck T., Mack J., Youssef K., Jarenwattananon N.N., et al.: IEEE Trans. Biomed. Eng. 99, 1 (2018).

16. Bartusik D., Tomanek B.: Arch. Biochem. Biophys. 493, 234 (2010).

17. Hills B.P., Duce S.L.: Magn. Reson. Imaging 8, 321 (1990).

18. Snaar J.E.M., Van As H.: Biophys. J. 63, 1654 (1992). 
19. Knight-Scott J., Brennan P., Palasis S., Zhong X.: JMRI 45, 710 (2017).

20. Krššák M., Roden M., Mlynárik V., Meyerspeer M., Moser E.: MRM Phys. Biol. Med. 16, 155 (2004).

21. Hammer B.E., Heath C.A., Mirer S.D., Belfort G.: 8, 327 (1990).

22. Callies R., Jackson M.E., Brindle K.M.:12,75 (1994).
23. Cox B.L., Erickson-Bhatt S., Szulczewski J.M., Squirrell J.M., Ludwig K.D., et al.: Magn. Reson. Med. 81, 3379 (2019).

24. Carvalho J., Alves S., Castro M., Geraldes C., Queiroz J.A., et al.: Pharmacol. Toxicol. Methods 95, 70 (2019).

25. Lippens G., Cahoreau E., Millard P., Charlier C., Lopez J., et al.: Analyst 143, 620 (2018).

26. Siegal G., Selenko P.: J. Magn. Res. 306, 202 (2019).

(C) 2020 by Polish Pharmaceutical Society. This is an open access article under the CC BY NC license (c) (i) () (http://creativecommons.org/licenses/BY/4.0/). 